\title{
The thermal and dynamical state of the atmosphere during polar mesosphere winter echoes
}

\author{
F.-J. Lübken ${ }^{1}$, B. Strelnikov ${ }^{1}$, M. Rapp ${ }^{1}$, W. Singer ${ }^{1}$, R. Latteck ${ }^{1}$, A. Brattli ${ }^{2}$, U.-P. Hoppe ${ }^{2}$, and M. Friedrich ${ }^{3}$ \\ ${ }^{1}$ Leibniz Institute of Atmospheric Physics, Kühlungsborn, Germany \\ ${ }^{2}$ Norwegian Defence Research Establishment (FFI), Kjeller, Norway \\ ${ }^{3}$ Institute of Communications Networks and Satellite Communications, Graz University of Technology, Austria
}

Received: 13 July 2005 - Published in Atmos. Chem. Phys. Discuss.: 29 August 2005

Revised: 16 November 2005 - Accepted: 30 November 2005 - Published: 2 January 2006

\begin{abstract}
In January 2005, a total of 18 rockets were launched from the Andøya Rocket Range in Northern Norway $\left(69^{\circ} \mathrm{N}\right)$ into strong VHF radar echoes called "Polar Mesosphere Winter Echoes" (PMWE). The echoes were observed in the lower and middle mesosphere during large solar proton fluxes. In general, PMWE occur much more seldom compared to their summer counterparts PMSE (typical occurrence rates at $69^{\circ} \mathrm{N}$ are $1-3 \%$ vs. $80 \%$, respectively). Our in-situ measurements by falling sphere, chaff, and instrumented payloads provide detailed information about the thermal and dynamical state of the atmosphere and therefore allow an unprecedented study of the background atmosphere during PMWE. There are a number of independent observations indicating that neutral air turbulence has caused PMWE. Ion density fluctuations show a turbulence spectrum within PMWE and no fluctuations outside. Temperature lapse rates close to the adiabatic gradient are observed in the vicinity of PMWE indicating persistent turbulent mixing. The spectral broadening of radar echoes is consistent with turbulent velocity fluctuations. Turbulence also explains the mean occurrence height of PMWE ( 68 $75 \mathrm{~km}$ ): viscosity increases rapidly with altitude and destroys any small scale fluctuations in the upper mesosphere, whereas electron densities are usually too low in the lower mesosphere to cause significant backscatter. The seasonal variation of echoes in the lower mesosphere is in agreement with a turbulence climatology derived from earlier sounding rocket flights. We have performed model calculations to study the radar backscatter from plasma fluctuations caused by neutral air turbulence. We find that volume reflectivities observed during PMWE are in quantitative agreement with theory. Apart from turbulence the most crucial requirement
\end{abstract}

Correspondence to: F.-J. Lübken

(luebken@iap-kborn.de) for PMWE is a sufficiently large number of electrons, for example produced by solar proton events. We have studied the sensitivity of the radar echo strength on various parameters, most important electron number density and turbulence intensity. Our observational and theoretical considerations do not provide any evidence that charged aerosol particles are needed to explain PMWE, in contrast to the summer echoes which owe their existence to charged ice particles.

\section{Introduction}

The existence and the properties of radar echoes can provide important information about the background atmosphere, for example on winds and turbulence. It is therefore crucial to understand their physical origin. It has become clear in recent years that VHF radar echoes from the summer mesopause region at mid and high latitudes are directly linked to charged ice particles which implies that temperatures are lower than $\sim 150 \mathrm{~K}$. These radar echoes are called (polar) mesosphere summer echoes, (P)MSE, and were first observed in the late 1970's (Czechowsky et al., 1979). A review on observations and our current understanding of PMSE has recently been published by Rapp and Lübken (2004). Occasionally, strong radar echoes have also been observed in the winter mesosphere and were later called "polar mesosphere winter echoes", PMWE (Czechowsky et al., 1979; Ecklund and Balsley, 1981; Kirkwood et al., 2002). Since atmospheric temperatures are generally much too high in the winter mesosphere to allow the existence of ice particles, Stebel et al. (2004) speculate that small charged aerosol particles (other than ice) are present and influence the plasma such that radar echoes can occur. The winter echoes are much less frequent than their summer

(C) 2006 Author(s). This work is licensed under a Creative Commons License. 


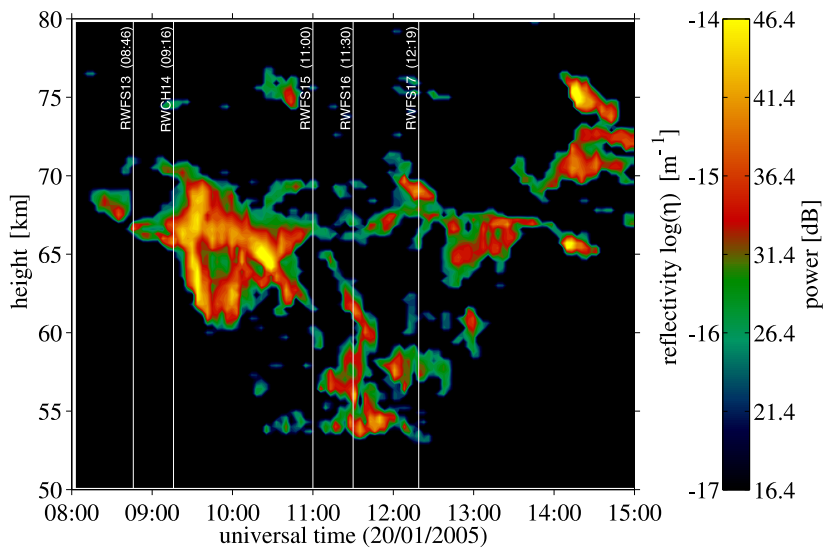

Fig. 1. Volume reflectivity $\eta$ detected by the ALWIN VHF radar on 20 January 2005, from 08:00-15:00 Universal Time (=09:0016:00 local time). The vertical lines indicate launch times of falling spheres. On the color scale we also give the backscatter power in relative units $(\mathrm{dB})$. The conversion from $\eta$ to $\mathrm{dB}$ is correct only at $65 \mathrm{~km}$. However, the error is small $(<4 \mathrm{~dB})$ in the height range $50-80 \mathrm{~km}$.

counterparts (occurrence rates of $1-3 \%$ and $\sim 80 \%$, respectively, at polar latitudes). This makes it extremely difficult to experimentally determine their characteristics and to study the physical processes involved. PMWE appear approximately between 55 and $80 \mathrm{~km}$ with a maximum occurrence around $68-75 \mathrm{~km}$ (see Zeller et al., $2005^{1}$, for more details). Nearly all of these echoes have been observed when the Sun photo-ionizes the mesosphere and when solar and/or geomagnetic activity provides an additional source of electrons.

In January 2005 we launched a sequence of meteorological and instrumented rockets into PMWE at high latitudes. Considering the very low occurrence rate of PMWE this opportunity was due to very favorable circumstances. These new measurements provide unique information about the conditions in the neutral and charged atmosphere. In this paper we summarize the temperature and wind measurements of the meteorological rockets (falling sphere and chaff) and provide some important results from the instrumented rockets. We will present observational and theoretical evidence that neutral air turbulence alone (i.e., without the presence of charged aerosols) can create PMWE.

\section{The ROMA/PMWE campaign}

In January 2005 a series of rockets were launched from the Andøya Rocket Range $\left(69^{\circ}\right)$ while the co-located ALWIN VHF radar detected strong echoes in the mesosphere. This

\footnotetext{
${ }^{1}$ Zeller, O., Zecha, M., Bremer, J., Latteck, R., and Singer, W.: Mean characteristics of mesosphere winter echoes at mid and high latitudes, J. Atmos. Solar Terr. Phys., submitted, 2005.
}

Table 1. Rockets launched during the ROMA/PMWE campaign in 2005 .

\begin{tabular}{|c|c|c|}
\hline date & time (UT) & label \\
\hline 18 Jan. & $11: 36: 30$ & RWMM01 \\
\hline , & 12:06:00 & RWMM02 \\
\hline$"$ & $12: 36: 00$ & RWFS03 \\
\hline " & 13:15:00 & RWFS04 \\
\hline$"$ & 13:58:00 & RWCH05 \\
\hline$"$ & $14: 42: 00$ & RWFS06 \\
\hline$"$ & $15: 31: 00$ & RWFS07 \\
\hline$"$ & $16: 07: 00$ & RWCH08 \\
\hline$"$ & $16: 54: 00$ & RWFS09 \\
\hline " & $17: 24: 00$ & RWFS10 1$)$ \\
\hline$"$ & 17:57:00 & RWCH11 \\
\hline$"$ & $18: 35: 00$ & RWFS12 \\
\hline 20 Jan. & 08:46:00 & RWFS13 \\
\hline , & 09:16:00 & RWCH14 \\
\hline " & 11:00:00 & RWFS15 \\
\hline$"$ & 11:30:00 & RWFS16 \\
\hline " & 12:19:00 & RWFS17 \\
\hline 21 Jan. & 13:06:00 & RWFS18 \\
\hline 25 Jan. & 01:30:00 & RWFS19 \\
\hline$"$ & 03:30:00 & RWFS20 \\
\hline$"$ & 05:30:00 & RWFS21 \\
\hline$"$ & 07:30:00 & RWFS22 \\
\hline 27 Jan. & $12: 22: 00$ & RWFS23 \\
\hline
\end{tabular}

$\mathrm{RW}=\mathrm{ROMA} /$ Winter, $\mathrm{FS}=$ falling sphere, $\mathrm{CH}=$ chaff $\mathrm{MM}=$ Mini-Midas; ${ }^{1}$ ) RWFS10 was a failure

campaign was part of a project called "Rocket borne Observations in the Middle Atmosphere" (ROMA). The dates and times of rocket launches are listed in Table 1. The ALWIN radar is part of the ALOMAR observatory (Arctic lidar observatory for middle atmosphere research) and is described in more detail elsewhere (Latteck et al., 1999). The radar operates at $53.5 \mathrm{MHz}$ which corresponds to a Bragg scale of $\ell_{B r}=\lambda / 2 \sim 3 \mathrm{~m}$. The power-aperture product of the radar is $5.3 \cdot 10^{7} \mathrm{~W} \cdot \mathrm{m}^{2}$ and the two-way beam half-width is $2.55^{\circ}$. Only the vertical beam is available during the winter period. In Fig. 1 the radar signal on 20 January 2005 is shown, when a series of 5 falling spheres were launched. A strong PMWE is observed with maximum backscattered power of more than $24 \mathrm{~dB}$ above noise floor (volume reflectivity: $4 \cdot 10^{-15} / \mathrm{m}$.). Such strong backscatter is observed rather seldom with our radar. The echoes come from an altitude range of roughly 55 to $75 \mathrm{~km}$, in agreement with typical occurrence heights.

In Fig. 2 typical profiles of volume reflectivity for winter (PMWE) and summer (PMSE) echoes are shown. As can be seen from this figure the winter echoes are weaker and lower compared to summer $\left(\eta \sim 10^{-15} / \mathrm{m}\right.$ at $60-70 \mathrm{~km}$, relative to $10^{-12}$ at $82-90 \mathrm{~km}$, respectively). In both cases the echoes have been integrated for approximately $1 / 2 \mathrm{~h}$. As can 
be seen from Fig. 1 the echoes in the period shown in Fig. 2 are rather strong but can on occasion be significantly weaker. We found that typical PMWE strengths are on the order of $10^{-16}-10^{-15} / \mathrm{m}$ during our campaign.

A total of 17 falling spheres, 4 chaff, and 2 instrumented rockets were launched from 18 to 27 January, most of them (12, 4, 2, respectively) during PMWE. On 25 and 27 January, i.e., during the last five rocket launches, the ALWIN radar did not detect any PMWE.

We will present only the main idea of the various in-situ experiments since they have been described in more detail elsewhere (Widdel, 1990; Schmidlin, 1991; Lübken, 1999; Friedrich et al., 2004; Brattli et al., 2005 ${ }^{2}$ ). From the falling sphere technique (FS), mass densities, temperatures, and horizontal winds from 95 to $35 \mathrm{~km}$ are derived using the deceleration and horizontal deflection of an inflated Mylar sphere which is transported to the lower thermosphere by a small rocket. The altitude resolution is $1-5 \mathrm{~km}$ depending on the altitude. The chaff technique relies on a foil cloud consisting of several thousand small aluminum strips slowly drifting through the atmosphere. This gives horizontal winds with much better resolution compared to FS, but in a rather limited height range of typically $15-20 \mathrm{~km}$.

Electron density profiles were measured using a rocket borne radio wave propagation experiment based on the Faraday rotation/differential absorption technique (see e.g., Mechtly et al., 1967). Because of the large electron density only the higher frequency $(3.883 \mathrm{MHz})$ yielded data, whereas $1.3 \mathrm{MHz}$ was already absorbed at the altitude where the antennas deployed.

Ion densities were measured using a positive ion probe (PIP) located in the front of each of the two instrumented payloads. An electric field in a spherical grid rejects electrons and collects positive ions with very high temporal and spatial resolution $(2.44 \mathrm{kHz}$ and $<1 \mathrm{~m}$, respectively). Mean ion densities are consistent with electron densities obtained from the wave propagation instrument.

It is obvious from the overall occurrence statistics of PMWE that a sufficient number of free electrons is required for these echoes. In wintertime these electrons come from solar radiation (as long as the Sun is above the horizon at mesospheric altitudes) and from solar and geomagnetic activity. The latter sources completely dominate over solar radiation during disturbed conditions. During the ROMA/PMWE campaign altitudes above $70 \mathrm{~km}$ were sunlit from $\sim 07: 00$ 15:00 UT (=08:00-16:00 LT). All PMWE observed during our campaign appeared during this time of day. Furthermore, the GOES-11 satellite showed strong energetic proton fluxes in the period 17-21 January which were enhanced by about 3 orders of magnitude compared to quiet conditions. In addi-

\footnotetext{
${ }^{2}$ Brattli, A., Hoppe, U.-P., Rapp, M., Lübken, F.-J., Singer, W., et al.: In-situ measurements of plasma parameters within polar mesosphere winter echoes, Atmos. Chem. Phys. Discuss., to be submitted, 2005.
}
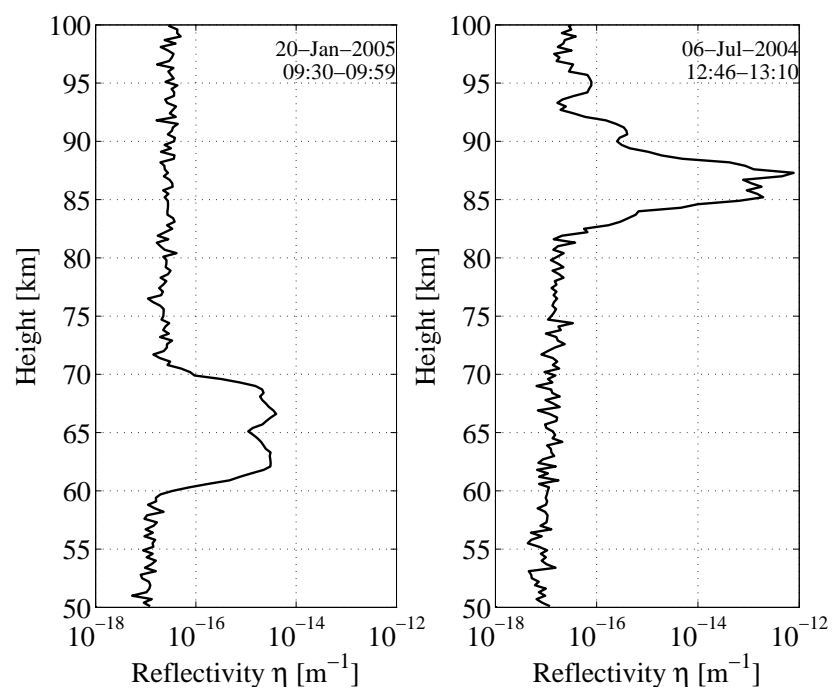

Fig. 2. Volume reflectivities deduced from the ALWIN radar backscatter power for a typical winter echo from 20 January 2005 (left panel), and for a summer echo on 6 July 2004 (right panel). In both cases the radar signal was averaged for $\sim 1 / 2 \mathrm{~h}$.

tion, on 18 January we observed strong riometer absorption at $38.2 \mathrm{MHz}(\sim 3 \mathrm{~dB})$ above our launch site and large fluctuations in magnetometer recordings both at Andenes and Troms $\emptyset(\Sigma \mathrm{K}$-indices $=54)$, indicating strong particle precipitation from the magnetosphere. Furthermore, on 20 January a very strong X-ray event of class X7.1 at $0.1-0.8 \mathrm{~nm}$ (corresponding to $7.1 \cdot 10^{-4} \mathrm{~W} / \mathrm{m}^{2}$ ) was observed by GOES-11. We summarize that the PMWE during our campaign occurred during a period of strong solar and geomagnetic disturbance leading to enhanced electron densities. This scenario supports the observations by Kirkwood et al. (2002), namely that PMWE can occur only if the number density of free electrons, $N_{e}$, is sufficiently large. We will later demonstrate in more detail the crucial importance of $N_{e}$ for a quantitative understanding of PMWE and will use measured electron number densities to calculate volume reflectivities.

\section{Experimental results}

In Fig. 3 all 11 temperature profiles measured during PMWE are shown. We designate the launches on 18, 20, and 21 January as PMWE launches, although during a few of these flights the PMWE had just disappeared or was very weak. We also take into account that the horizontal distance between the atmospheric volume measured by the radar (sounding vertically) and the falling spheres and chaff is typically $30-50 \mathrm{~km}$. There is a clear tendency in the profiles shown in Fig. 3 for a steep temperature gradient in the $50-70 \mathrm{~km}$ height range. In some cases the temperature gradient is close to the adiabatic lapse rate. We argue that these steep gradients are an indication of turbulent mixing (see below for 


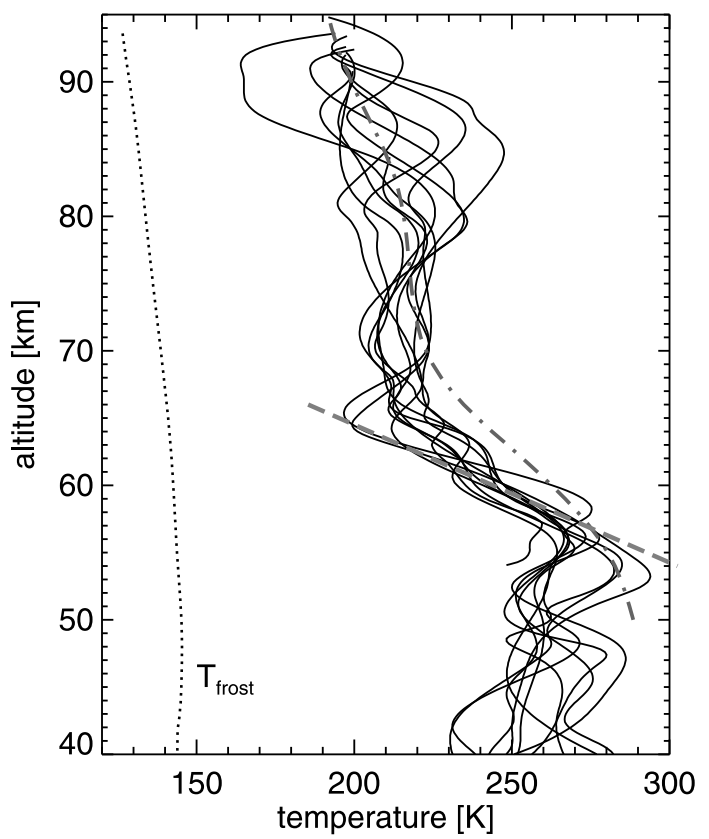

Fig. 3. Temperature profiles from falling spheres in the presence of PMWE. Profiles from flights RWFSxx, $\mathrm{xx}=03,04,06,07,09,12$, $13,15,16,17,18$ are shown (see Table 1 for more details). The dotted line shows the frost point temperature. The dashed-dotted line is the mean January temperature profile from the FS climatology of Lübken and von Zahn (1991). The dashed line indicates an adiabatic temperature lapse rate of $9.8 \mathrm{~K} / \mathrm{km}$.

more details). In Fig. 3 we also show the mean temperature profile for January from the climatology of Lübken and von Zahn (1991), hereafter referred to as L\&vZ. This climatology is based on FS measurements, i.e., on the same experimental technique as used here. The mean temperature gradient at PMWE altitudes is significantly smaller in the L\&vZ-climatology compared to the measurements in our campaign. This indicates that the thermal structure during our rocket flights was considerably different compared to the climatological mean. We note, however, that the temperature gradient in the L\&vZ climatology is smaller (i.e., more negative) in the 60-70 km altitude range, compared to above and below. Therefore, the atmosphere is closer to instability in this height range. It is important to note that the FS technique is not influenced by the presence of aerosol particles (if there should be any) since they cannot exert a noticeable drag on the sphere. In contrast, temperature profiles deduced from lidar measurements might be influenced by aerosols as has been demonstrated, for example, in Stebel et al. (2004) in their Figs. 3 and 4.

In Fig. 4 we show Richardson numbers $R i=\omega_{B}^{2} /(\partial \bar{u} / \partial z)^{2}$ calculated from the falling sphere temperatures, and winds from chaff and falling sphere, respectively $\left(\omega_{B}=\right.$ BruntVäisälä frequency; $\bar{u}=$ mean horizontal wind). Since the altitude resolution of the falling sphere winds is significantly

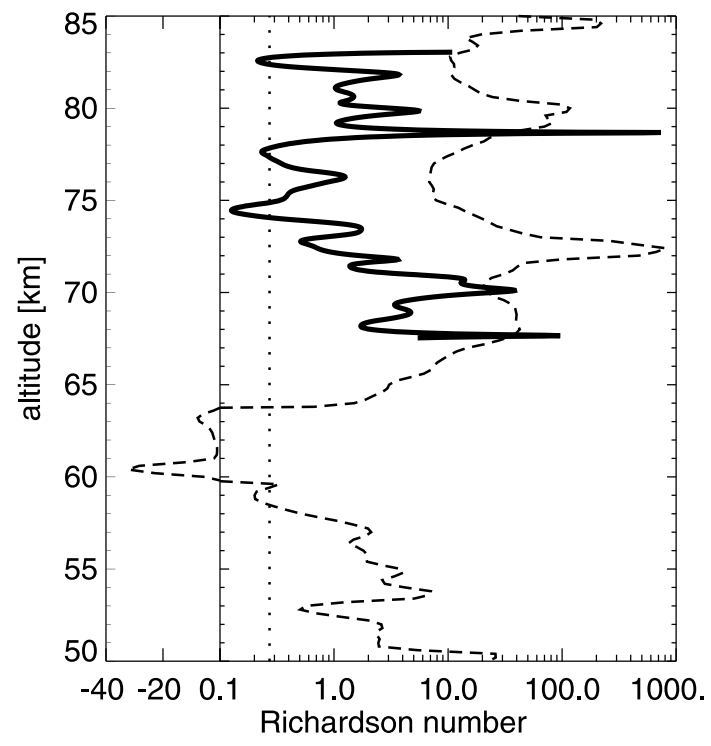

Fig. 4. Richardson number calculated from chaff winds (RWCH14) and falling sphere temperatures (RWFS17, solid line). Dashed line: same but using winds and temperatures from falling sphere (RWFS17). Note the change of scales for negative $R i$ numbers. The dotted vertical line indicates $R i=1 / 4$. There is a time difference of $\sim 3 \mathrm{~h}$ between the two rocket launches.

poorer compared to chaff, the wind shears are systematically smaller and the Richardson number is larger. As can be seen from Fig. 4 the difference is typically one order of magnitude. This implies that FS winds have to be considered with great care when identifying instability regions as has been done in Kirkwood et al. (2003). Richardson numbers from chaff winds in Fig. 4 are very structured and show layers with small values indicating instability roughly above $70 \mathrm{~km}$. Unfortunately, the chaff profile does not cover the entire range of PMWE. Taking into account the limitations about FS winds mentioned above, we still see that $R i$ is very small (and even negative) at altitudes around $60 \mathrm{~km}$. We will later come back to a comparison of $R i$ with PMWE.

We have used a wavelet analysis to determine power spectral densities (PSD) of relative ion density fluctuations defined as $\Delta N_{i}=\left(N_{i}-\left\langle N_{i}\right\rangle\right) /\left\langle N_{i}\right\rangle$, where $N_{i}$ is ion number density, and $\left\langle N_{i}\right\rangle$ is a running mean of $N_{i}$ over 6 rocket spin periods (Torrence and Compo, 1998; Strelnikov et al., 2003). Figure 5 shows two spectra from the downleg of flight RWMM01. One of the spectra is from an altitude range within PMWE (58.5-59.0 km), the other from outside PMWE (68.0-68.5 km). Power spectral densities are much larger inside PMWE which implies large fluctuations. The spectrum from inside PMWE shows a slope close to $k^{-5 / 3}$, compatible with an inertial subrange of a Kolmogorov turbulence spectrum. On the other hand, the PSD from outside PMWE is much smaller and "flat", basically determined by instrumental noise. The spectra from the second flight (RWMM02, not discussed here) show a similar characteristic 
behavior. We note, though, that both flights are only $30 \mathrm{~min}$ apart, i. e., they are presumably launched into a single event. We conclude that spectra of ion density fluctuations are consistent with turbulence inside PMWE, and no turbulence outside.

\section{Theory of turbulent PMWE}

The theory of coherent radar backscatter from a weakly ionized plasma is summarized in Tatarskii (1961) and yields the following expression for the volume reflectivity:

$\eta^{c o h}=8 \pi^{2}\left(\frac{e^{2} \overline{N_{e}}}{2 \epsilon_{\circ} m_{e} c^{2}}\right)^{2} \cdot \Phi_{N e}(\kappa)$

where $e$ is the elementary charge, $\overline{N_{e}}$ is the mean electron density, $\epsilon_{\circ}$ is the dielectric constant of vacuum, $m_{e}$ is the electron mass, $c$ is the speed of light, and $\Phi_{N e}(\kappa)$ is the three-dimensional power spectral density (PSD) of the relative electron density fluctuations at the radar Bragg wave number $\kappa=2 \cdot(2 \pi / \lambda)=2 \pi / \ell_{B r}$. A general expression for $\Phi_{N e}$ was given by Driscoll and Kennedy (1985) and was later applied to in-situ measurements of neutral and electron density fluctuations (Lübken et al., 1994; Giebeler, 1995). At scales within the inertial subrange (and smaller) the following expression for the radar reflectivity was derived:

$$
\begin{aligned}
\eta= & 16 \cdot \pi^{2}\left(\frac{e^{2} \overline{N_{e}}}{2 \epsilon_{\circ} m_{e} c^{2}}\right)^{2} Q^{9 / 2} \text { A } N_{\vartheta} \epsilon^{-1 / 3} \eta_{K o l}^{11 / 3} \\
& \cdot\left(y^{-11 / 3}+y^{-3}\right) \cdot \exp \left\{-\frac{\alpha}{Q^{2} S c}\left(\frac{3}{2} y^{4 / 3}+y^{2}\right)\right\}
\end{aligned}
$$

where $y=Q^{3 / 2} \cdot \eta_{K o l} \cdot k$ ( $k=$ wavenumber $), \eta_{K o l}=\left(v^{3} / \epsilon\right)^{1 / 4}$ is the Kolmogorov micro scale, $v$ is the kinematic viscosity of air, $\epsilon$ is the turbulent energy dissipation rate, $N_{\vartheta}$ is the dissipation rate of fluctuations, $\mathrm{Sc}=v / D$ is the $\mathrm{Schmidt}$ number, $D$ is the diffusivity of the tracer, and $Q=2, A=0.033 \cdot a^{2}$, $a^{2}=1.74, \alpha=0.83$ are numerical constants. Further explanations on the quantities introduced in Eq. (2) are given in the references mentioned above and in Lübken (1992). Note that the size of the aerosol particles enters through a reduced diffusivity, D, which increases the Schmidt number $S c=v / D$ to values larger than unity. The normalization of $\Phi_{N e}$ in Eq. (2) is such that the integral of the PSD gives the total variance of the fluctuations:

$$
\left\langle\vartheta^{\prime 2}\right\rangle=\int_{-\infty}^{\infty} \int_{-\infty}^{\infty} \int_{-\infty}^{\infty} \Phi_{N e}(\boldsymbol{k}) d k_{x} d k_{y} d k_{z}
$$

In Fig. 6 we have plotted various cases of Eq. (2), keeping the energy dissipation rate constant $(\epsilon=0.1 \mathrm{~W} / \mathrm{kg})$ and varying $N_{e}, S c$, and $N_{\vartheta}$. A value of $\epsilon=0.1 \mathrm{~W} / \mathrm{kg}$ was chosen since it is a moderate value and it is consistent with model results (Becker, 2004). As can be seen from Fig. 6 the PSD

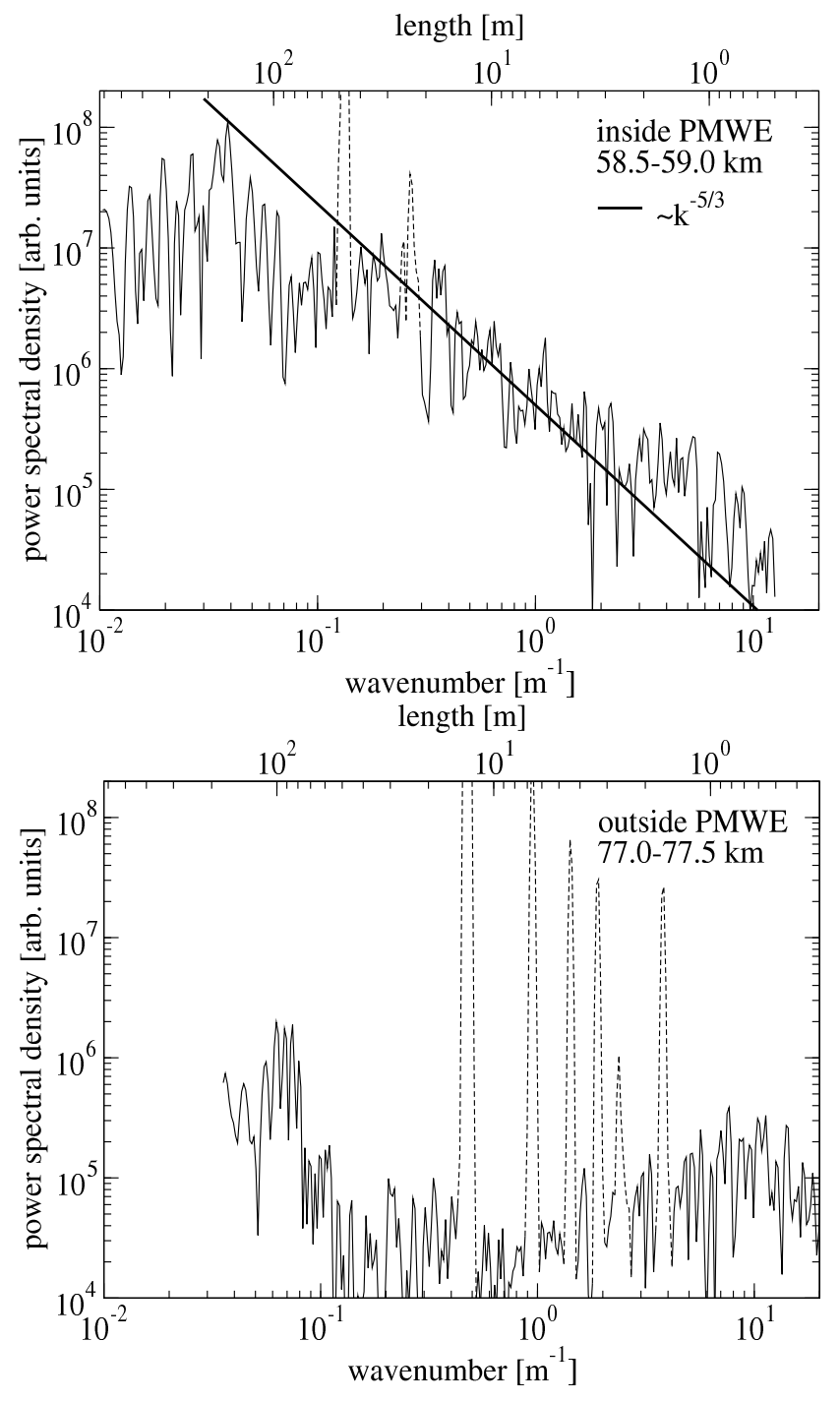

Fig. 5. Power spectral density of relative ion fluctuations as measured by the PIP instrument during flight RWMM01. Upper panel: spectrum from an altitude range within PMWE. The straight line indicates a $-5 / 3$ power law expected from classical turbulence theory. Lower panel: spectrum from an altitude range without PMWE. The prominent peaks in the spectra (dashed lines) are caused by the payload spin frequency and its harmonics.

at $3 \mathrm{~m}$ varies strongly with $N_{e}$ and to a lesser extent with $N_{\vartheta}$ and with Sc. We will discuss the sensitivity of the volume reflectivity in more detail below.

It is important to note that the "breaks" in the spectra in Fig. 6 vary strongly with kinematic viscosity, $v \propto 1 / \rho$, and therefore with altitude. The scale corresponding to the break is defined as (see Lübken, 1997):

$\ell_{\circ}^{H}=9.90 \cdot \eta_{K o l}=9.90 \cdot\left(\frac{v^{3}}{\epsilon}\right)^{1 / 4}$ 


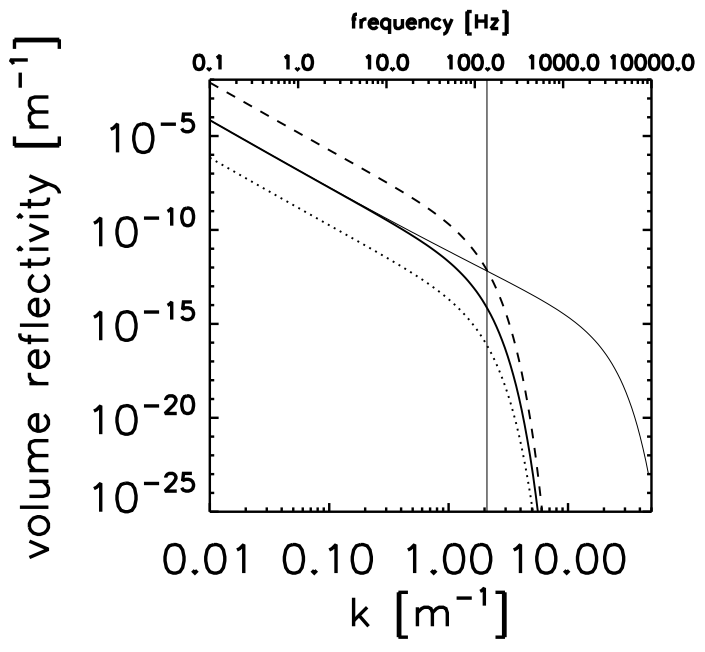

Fig. 6. Volume reflectivity as a function of wave number for various cases of electron densities $N_{e}$, Schmidt number Sc, and $N_{\vartheta}$. Standard case (thick solid curve): $N_{e}=1 \cdot 10^{10} / \mathrm{m}^{3}, N_{\vartheta}=1 \cdot 10^{-5} / \mathrm{s}$, and $\mathrm{Sc}=1$. Relative to the standard case the electron density has been decreased by a factor of 10 (dotted line), $N_{\vartheta}$ has been increased by a factor of 100 (dashed line), and the Schmidt number has been increased by a factor of 100 (thin solid line). The energy dissipation rate is $\epsilon=0.1 \mathrm{~W} / \mathrm{kg}$ and the kinematic viscosity is $\nu=0.245 \mathrm{~m}^{2} / \mathrm{s}$ for all curves. The value for $v$ is representative for an altitude of $70 \mathrm{~km}$. The thin vertical line corresponds to the Bragg scale of the ALWIN radar.

In Fig. 7 we show turbulent energy dissipation rates $\epsilon$ and the corresponding heating rates $(\mathrm{dT} / \mathrm{dt})$ required to fulfill the condition $\ell_{0}^{H}=\ell_{B r}$, which is a very rough criterion to allow turbulence producing substantial fluctuations for radar wave scatter. From Eq. (4) we see that $\epsilon \sim v^{3} \sim 1 / \rho^{3}$, i.e., the required turbulence intensity increases rapidly with altitude. It is obvious from this plot that unrealistic strong turbulence (heating rates of up to 1 million $\mathrm{K} / \mathrm{d}$ !) would be required to produce fluctuations at VHF radar scales in the upper mesosphere, whereas moderate or even small turbulence (heating rates: $0.1-10 \mathrm{~K} / \mathrm{d}$ ) is sufficient in the lower mesosphere.

We have systematically studied the sensitivity of the volume reflectivity, $\eta$, on electron number densities, $N_{e}$, turbulent energy dissipation rates, $\epsilon$, Schmidt numbers, Sc, and on $N_{\vartheta}$. The variation of $\eta$ with $N_{e}^{2}$ comes from the fact that relative electron density fluctuations are considered in deriving Eqs. (1) and (2), whereas the radar signal comes from absolute electron number density fluctuations. We argue that relative electron (and ion) density fluctuations created by neutral air turbulence are fairly similar in all cases of turbulence, whereas absolute electron density fluctuations can vary substantially depending on the mean background electron density. This idea comes from the simple consideration that the "mixing ratio" of ions and electrons (relative to neutrals) is constant when an air parcel is moved vertically. Since the background gradient in the plasma is normally dif-

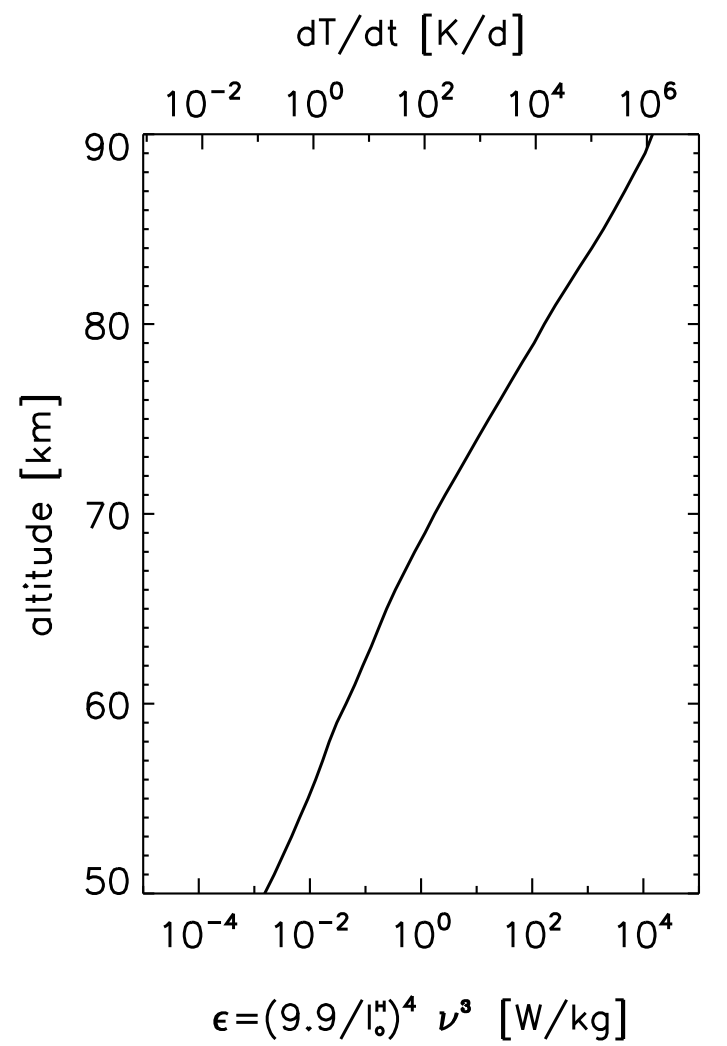

Fig. 7. Turbulent energy dissipation rates derived from the condition $\ell_{\mathrm{o}}^{H}=\ell_{B r}\left(\ell_{B r}=3 \mathrm{~m}\right)$ which is a very rough criterion to allow turbulence producing substantial fluctuations for radar wave scatter. The upper axis shows the corresponding heating rates calculated from $d T / d t=\epsilon / c_{p}$ ( $c_{p}=$ heat capacity of air at constant pressure).

ferent from the neutral atmosphere, relative ion fluctuations $\left(\Delta N_{i} / N_{i}\right)$ are larger compared to neutrals $(\Delta n / n)$. Simple scale height considerations lead to the following relationship (see Thrane and Grandal, 1981, for more details):

$$
\frac{\Delta N_{i}}{N_{i}}=\frac{1}{F} \cdot \frac{\Delta n}{n} \quad ; \quad F=\frac{\gamma \frac{H_{p}}{H_{n}}-1}{\gamma \frac{H_{p}}{H_{i}}-1}
$$

where $H_{p}, H_{n}$ and $H_{i}$ are the scale heights of pressure, neutral density, and ion density, respectively. Indeed, there have been several in-situ measurements of ion and electron number densities during winter conditions which show fluctuations on the order of 1-5\% (much larger than neutral air fluctuations) and conversion factors (1/F) of approximately 5-10 (Thrane and Grandal, 1981; Thrane et al., 1985, 1994; Lübken et al., 1987, 1993; Blix et al., 1990a,b).

The quantity $N_{\vartheta}$ determines the total variability of the tracer, together with $N_{e}$ and $\epsilon$. We have determined $N_{\vartheta}$ from our neutral air turbulence measurements in 12 sounding rocket flights and found typical values of $10^{-8}$ to $10^{-6} / \mathrm{s}$. From Eqs. (3) and (5) we see that for electrons the quantity $N_{\vartheta}$ must be larger by a factor of approximately 


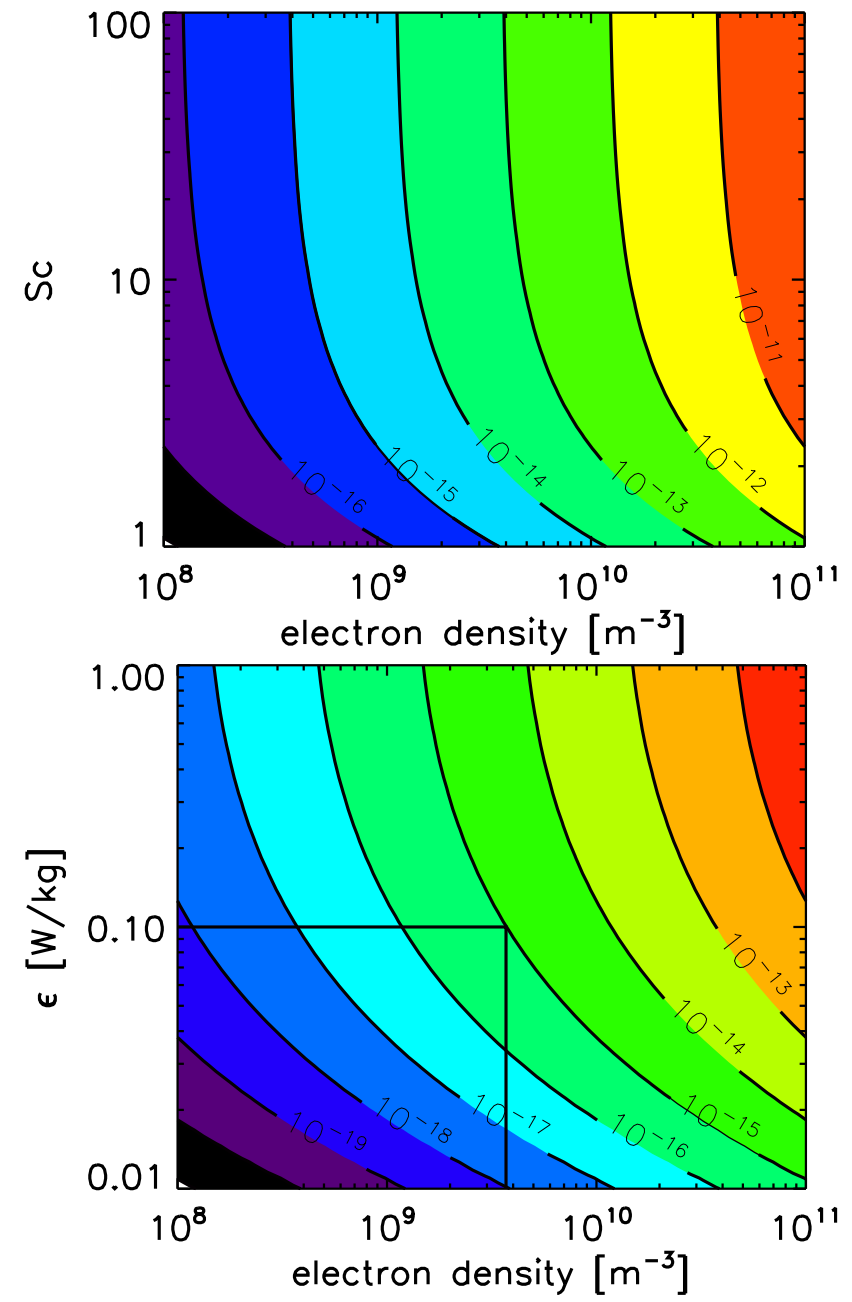

Fig. 8. Upper panel: The sensitivity of the volume reflectivity at $3 \mathrm{~m}$ to electron density and Schmidt number for $\epsilon=0.1 \mathrm{~W} / \mathrm{kg}$ and $N_{\vartheta}=1 \cdot 10^{-5} / \mathrm{s}$. Lower panel: Same, but for electron density and turbulent energy dissipation rate $\left(\mathrm{Sc}=1 ; N_{\vartheta}=1 \cdot 10^{-5} / \mathrm{s}\right)$. A kinematic viscosity of $\nu=0.245 \mathrm{~m}^{2} / \mathrm{s}$ is used, representative for an altitude of $70 \mathrm{~km}$.

$1 / F^{2} \sim 25 \ldots 100$. We have therefore taken $N_{\vartheta}=1 \cdot 10^{-5} / \mathrm{s}$ as our standard case. This number is compatible with a direct determination of $N_{\vartheta}$ from a comparison of neutral air and plasma fluctuation spectra (Lübken et al., 1994; Giebeler, 1995).

In Fig. 8 we show the volume reflectivity $\eta_{3 m}$ calculated from Eq. (2) at $\ell_{B r}=3 \mathrm{~m}$. Note that we have used a kinematic viscosity of $\nu=0.245 \mathrm{~m}^{2} / \mathrm{s}$ corresponding to an altitude of $70 \mathrm{~km}$. It is obvious from Fig. 8 that $\eta_{3 m}$ varies much stronger with electron density than with Schmidt number. Furthermore, the intensity of turbulence (namely $\epsilon$ ) plays an important role for $\eta_{3 m}$. On the other hand, weak turbulence can be compensated for by large electron number densities. For example, for a volume reflectivity of $\eta=10^{-15} / \mathrm{m}$ (typical for PMWE) a decrease of $\epsilon$ from 0.1 to $0.01 \mathrm{~W} / \mathrm{kg}$

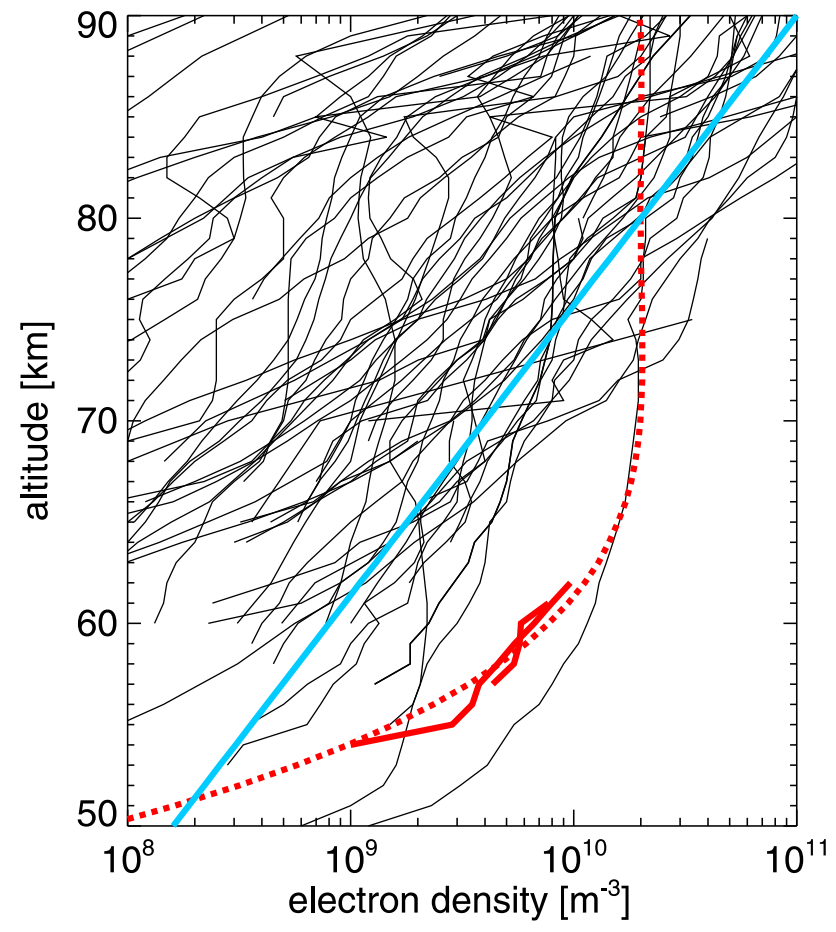

Fig. 9. Electron density profiles measured by the Faraday technique in flights RWMM01 and RWMM02 (thick red lines), pragmatically extended to larger and smaller altitudes (red dotted line). We also show a compilation of daytime electron density measurements from the Faraday technique from the auroral zone (thin lines) and a straight line representing "typical" electron densities during disturbed conditions (blue line, see text for more details).

can be compensated for by an increase of $N_{e}$ from $4 \cdot 10^{9}$ to $1 \cdot 10^{11} / \mathrm{m}^{3}$. It is clear from Fig. 8 that any speculation about the presence of particles based on Schmidt numbers is only meaningful if accompanied by precise measurements of electron number densities and turbulence.

We now apply the theoretical considerations from above to our measurements during the ROMA/PMWE campaign. In Fig. 9 the electron density profile measured by the Faraday instrument during flights RWMM01 and RWMM02 are shown together with a simple analytical approximation and extrapolation to altitudes below and above the actual measurements. We also show in that figure a compilation of (possibly all ever measured) daytime electron density measurements from rocket borne wave propagation from the auroral zone. The riometer absorption at the time of these measurements varied largely from 0 to $4.5 \mathrm{~dB}$. Typical riometer values during our salvo are 1.5-3.2 dB. The electron densities measured during our PMWE campaign were indeed exceptionally large, in fact the largest in the entire collection of comparable measurements, except for one profile observed at Ft. Churchill $\left(59^{\circ} \mathrm{N}\right)$ during a polar cap absorption (PCA) event. The extended electron density profile from the Faraday measurement during our campaign is used to determine 

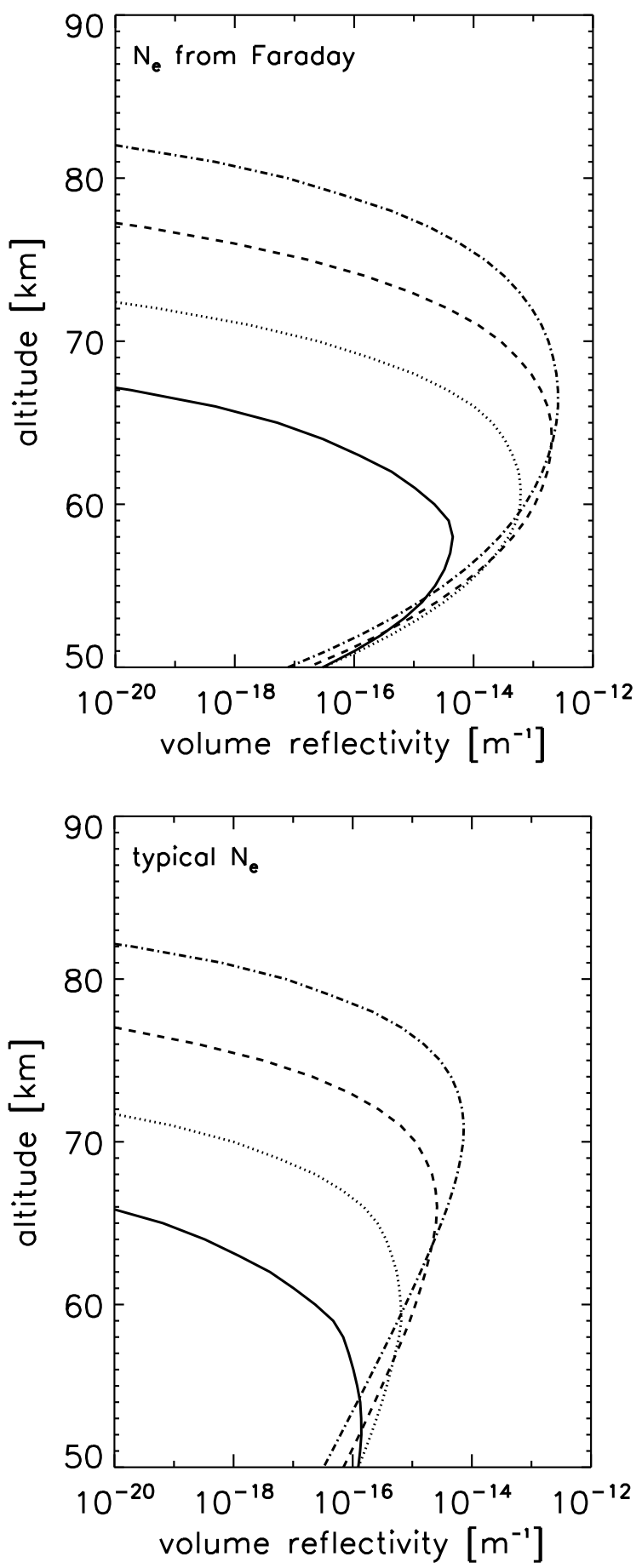

Fig. 10. Upper panel: Volume reflectivity at the ALWIN radar Bragg scale for various turbulence strength, namely $\epsilon=0.001$ (solid), $=0.01$ (dotted),$=0.1$ (dashed), and 1. (dashed-dotted). All values in $\mathrm{W} / \mathrm{kg}$. The electron density profile from the extended Faraday profile in Fig. 9 has been used. Lower panel: Same as upper panel but with 'typical' electron profile from Fig. 9. For all profiles we have used $N_{\vartheta}=1 \cdot 10^{-5} / \mathrm{s}$. the volume reflectivity from Eq. (2) assuming very weak, weak, moderate, and strong turbulence $(\epsilon=0.001,0.01,0.1$, and $1 \mathrm{~W} / \mathrm{kg}$, respectively), independent of altitude. It is important to note that we have assumed that no aerosols and no negative ions are present in the atmosphere, i.e., $\mathrm{Sc}=1$. The results are shown in Fig. 10 (upper panel). As can be seen, moderate and even weak turbulence can produce a reflectivity of $10^{-14}-10^{-13} / \mathrm{m}$ which is even larger than typical PMWE values (see Fig. 2). We note, however, that the electron densities are significantly larger compared to typical disturbed conditions, and to MF and EISCAT measurements prior and after the flight (W. Singer, private communication). We have sketched a more typical electron density profile during disturbed conditions in Fig. 9 which is presumably more representative for general PMWE conditions. The corresponding volume reflectivities are on the order of $10^{-16}-10^{-15} / \mathrm{m}$ (see Fig. 10, lower panel), in close agreement with observations.

\section{Discussion}

The volume reflectivities shown in Fig. 10 nicely agree with the mean altitude statistics of PWME with a maximum appearance around $70 \mathrm{~km}$. Assuming that turbulence of various strengths occurs in the entire mesosphere, the height range of PMWE is limited by two effects. Firstly, viscosity is very large at higher altitudes and dampens all small-scale fluctuations. On the other hand, too few electrons are available below $55 \mathrm{~km}$ to allow significant radar backscatter. We note, that the turbulence climatology presented in Lübken (1997) shows rather small turbulence in the winter mesosphere with typical $\epsilon$ values of $0.001-0.01 \mathrm{~W} / \mathrm{kg}$. Still, even for weak turbulence the volume reflectivity is large enough to result in PMWE, provided the electron densities are large enough. We should keep in mind that the compilation in Lübken (1997) is based on 12 flights only. It is conceivable that on occasions turbulence can be stronger than in these flights. The maximum volume reflectivity observed by the radar is in quantitative agreement with the estimates presented above assuming turbulence without aerosols.

The turbulence climatology published in Lübken (1997) explains why no echoes are observed in the summer lower mesophere. In summer we have very seldom observed any turbulence below $76 \mathrm{~km}$ in a total of 13 flights. The exception comes from the flights in the summer of 2002 which, however, has been very special in terms of the general atmospheric circulation and wave activity (Goldberg et al., 2004; Becker et al., 2004; Rapp et al., 2004). At that time our radar did not yet cover the lower mesosphere, i. e., we don't know whether an echo would have been observed. In the year 2004 we have expanded the height coverage of our radar to 50 $115 \mathrm{~km}$ but have not observed any echo from the lower summer mesosphere since then. 
The fact that PMWE are frequently observed once electron densities are large enough indicates that the second ingredient, namely turbulence, is likely to persist in the lower winter mesosphere. Unfortunately, our experimental knowledge about mesospheric turbulence during winter is very limited. Regarding modeling we refer to recent results on gravity wave saturation which indeed suggests the presence of turbulence in the lower winter mesosphere (Fritts and Alexander, 2003; Becker, 2004).

There are several indications that turbulence was indeed present during PMWE. The PIP instrument detected smallscale fluctuations of positive ion densities which are a good tracer for neutral air fluctuations. The spectra of these fluctuations (Fig. 5) clearly show strong fluctuations with turbulence spectral characteristics inside the PMWE layer, whereas fluctuations are basically absent outside the layer.

The near-adiabatic temperature profiles shown earlier indicate that turbulent mixing must have been present for a substantial period. In Fig. 11 we show the temperature profiles from flights RWFS16 and RWFS17 together with the radar echoes during these flights. More precisely, the radar echo profiles averaged in a period of approximately $15 \mathrm{~min}$ around the launch times are shown. There is a region of nearadiabatic lapse rates close to the PMWE layer. The slight mismatch in altitude by a few $\mathrm{km}$ can be explained by a small tilt of the layers by $\sim 0.1 \mathrm{~km} / \mathrm{km}$. We note that a steep temperature gradient is also present in the lidar profile shown in Stebel et al. (2004) in the case that no aerosols are present ("Alternative 2" in their Fig. 4).

The apparent absence of radar echoes in the center of the turbulent layer during flight RWFS17 is in agreement with the theory of Fritts et al. (2003) and has been observed for other tracers in the troposphere (see Fig. 5 in the Fritts et al. (2003) paper). The explanation of this effect is that persistent turbulent mixing destroys the background gradient of the tracer and thereby inhibits the generation of fluctuations even if turbulence is still active.

Another indication for turbulence comes from the Richardson numbers in Fig. 4 which indicate unstable regions (i.e., $R i$ smaller as 1/4) at PMWE altitudes and above. In general, regions of PMWE seen in Fig. 1 agree with the appearance of instability shown in Fig. 4. For example, $R i$ is very low in the $60-65 \mathrm{~km}$ altitude region, where strong radar echoes are observed. A one-to-one relationship cannot be expected due to the patchy and intermittent character of turbulence, the time constants of turbulence production and destruction, and the horizontal difference between the radar volume and the rocket probing volume. We note that recent model simulations of gravity wave breaking have shown that turbulence can be generated even if the Richardson number is significantly larger than unity (Achatz and Schmitz, 2006).

Further evidence for turbulence at PMWE altitudes comes from the spectral width of the radar echo shown in Fig. 12. Large spectral broadening corresponding to velocity fluctuations of up to $\sigma_{\mathrm{obs}} \sim 10 \mathrm{~m} / \mathrm{s}$ are observed within PMWE.
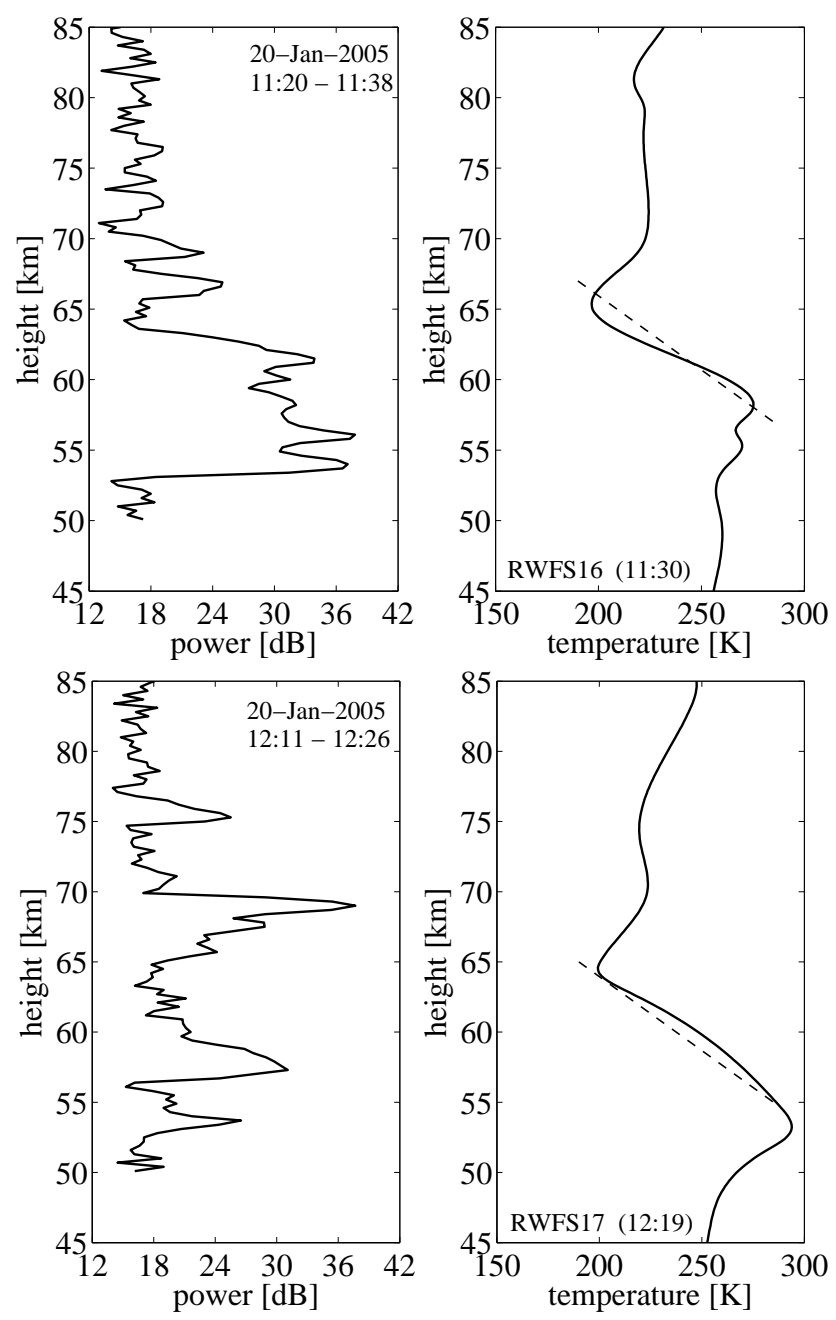

Fig. 11. Comparison of temperature profiles (right panels) with radar power profiles (left panels) for flights RWFS16 and RWFS17. The radar signal was averaged for a time period of $\sim 15 \mathrm{~min}$, roughly centered at the launch time. The dashed lines indicate an adiabatic lapse rate.

We hesitate to convert these values to turbulence parameters since part of the observed broadening might be due to instrumental effects such as beam and shear broadening (Hocking, 1983). We have used a typical horizontal wind speed from our falling sphere flights of $v \sim 60 \mathrm{~m} / \mathrm{s}$ to roughly estimate the instrumental broadening and arrive at $\sigma_{\text {instr }} \sim \mathrm{V} \cdot \sin \left(2.55^{\circ}\right) \sim 2.7 \mathrm{~m} / \mathrm{s}$. Using $\sigma_{\text {turb }}=\sqrt{\sigma_{\text {obs }}^{2}-\sigma_{\text {instr }}^{2}}$ this leads to somewhat smaller turbulent broadening, $\sigma_{\text {turb }}$. However, a significant part of the observed broadening is caused by atmospheric velocity fluctuations presumably caused by turbulence. We note that we cannot study the aspect sensitivity of backscatter since only the vertical beam was in operation during the campaign.

Our falling sphere temperature measurements clearly show that the atmospheric temperature is much larger than 


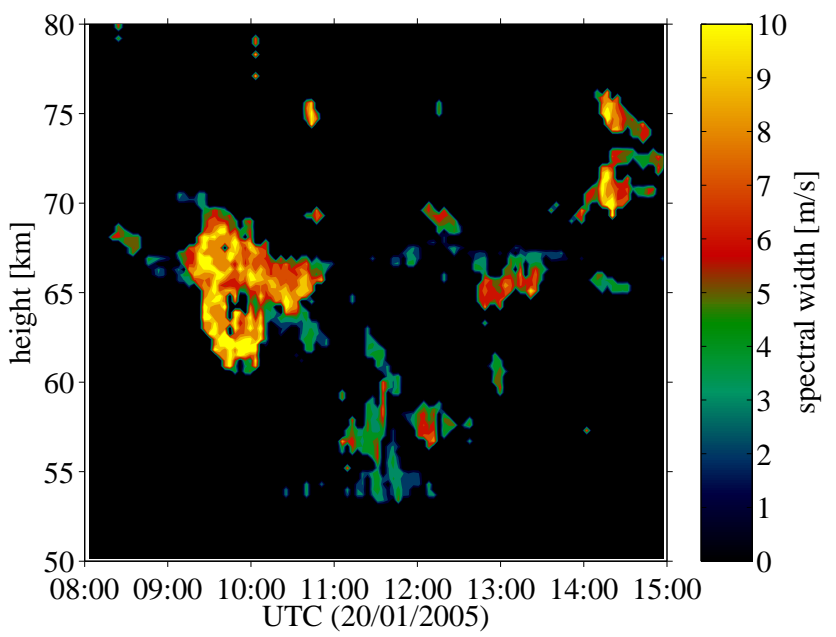

Fig. 12. Spectral width of the radar signal expressed in $\mathrm{m} / \mathrm{s}$ for the PMWE shown in Fig. 1.

the frost point temperature (by more than $50 \mathrm{~K}$ ). In other words, it is much too warm to allow the existence of water ice particles. The question remains whether other 'large' charged aerosols are present which could influence the radar backscatter. The observations and the theoretical considerations presented above did not give any evidence for aerosols. Contrary to the summer mesopause region, aerosols are not needed to explain the winter echoes. On the other hand, from our measurements we cannot positively exclude that aerosols are present. Certainly, they cannot be large (radius larger than 20-30 nm) because they would then cause a significant enhancement in the lidar signal. Schmidt numbers significantly larger than unity indicate the presence of charged aerosols and have indeed been determined from insitu measurements of neutral and plasma fluctuations in the vicinity of summer echoes (Lübken et al., 1994). Similar attempts would be rather difficult for the winter echoes since the Schmidt number is presumably much smaller than in summer because aerosols are smaller (see above).

We note that the presence of a sufficiently large number of negative ions will take care of the charge balance with positive ions and will thereby enhance the mobility of free electrons (Stebel et al., 2004; Hill, 1978). This would lead to Schmidt numbers smaller than one. We have not considered this case since daylight and particle precipitation inhibits the attachment of electrons to form negative ions. Whether or not a sufficient number of negative ions can form during night under geomagnetic disturbed conditions is not yet clear. We note, that no electron or negative ion density measurements have been performed during night in the presence of PMWE.

Apart from turbulence the most crucial requirement for PMWE is a sufficiently large electron number density. During disturbed conditions precipitating particles from the Sun or from the Earth's magnetosphere create electron number densities which can be orders of magnitude larger compared to normal conditions. During night part of these electrons are attached to neutrals to form negative ions. These electrons are immediately detached by solar radiation once the Sun rises or when proton/electron precipitation occurs. This explains why PMWE are almost exclusively observed during the day and during strong disturbance, such as solar proton events. On the other hand, a typical value for $\overline{N_{e}}$ during undisturbed conditions in the winter lower mesosphere during daytime is $10^{8} / \mathrm{m}^{3}$, i.e., two orders of magnitude less than during disturbed conditions. Since $\eta \sim{\overline{N_{e}}}^{2}$ this implies that PMWE should be smaller by $40 \mathrm{~dB}$, assuming all other parameters to be unchanged. This is much too small to be detectable by our radar. From Fig. 9 we see that electron densities can vary by several orders of magnitude depending on the source strength (solar/geomagnetic) and on other factors involving ion-chemistry and photo-chemistry. The sources and sinks cannot be modeled accurately enough to predict the electron profile for all conditions with sufficient accuracy. Therefore, a precise theoretical prediction of volume reflectivity from turbulence requires a precise measurement of electron number densities, e.g. by the Faraday rotation technique.

\section{Summary and conclusions}

Various experimental observations support the idea that PMWE during the ROMA/PMWE campaign are caused by neutral turbulence, namely

- The spectrum of ion density fluctuations shows turbulence like characteristics within PMWE, and no fluctuations outside PMWE.

- Persistent steep temperature gradients close to the adiabatic lapse rate in the vicinity of the PMWE layer indicate turbulent mixing. In one case we observe a text book example of fluctuations at the edges of the turbulent layer in agreement with theory.

- Temperature measurements from FS and high resolution wind measurements by chaff show very low Richardson numbers indicating instability.

- Spectral broadening of the VHF signal indicates velocity fluctuations of several $\mathrm{m} / \mathrm{s}$, presumably due to turbulence.

- Turbulence explains the general altitude dependence of PMWE with a maximum around $70 \mathrm{~km}$ (too large viscosity above $80 \mathrm{~km}$ and too few electrons below $60 \mathrm{~km}$ ).

- Volume reflectivities calculated from turbulence theory agrees quantitatively with observations.

- The seasonal variation of turbulence explains the nonexistence of echoes in the summer lower mesosphere. 
We have based our general considerations about turbulent PMWE on as many measurements of turbulent parameters as available, in particular regarding $\epsilon$ and $N_{\vartheta}$. Other studies hinge on uncertain estimates of 'constants' which are only poorly known and further suffer from idealistic assumptions of turbulence generation etc. Since this leads to uncertainties in the calculated volume reflectivities of several orders of magnitude, a relatively small discrepancy between measured and theoretical values of $\eta$ cannot be used to rule out turbulence as a cause of PMWE.

Our observations and theoretical considerations show that aerosols are not needed to explain PMWE (as opposed to summer echoes). On the other hand, we cannot positively exclude their existence from our data as long as they are smaller than $\sim 20 \mathrm{~nm}$. We have stated earlier that any speculation about the presence of aerosols based on Schmidt numbers is only meaningful if accompanied by precise measurements of electron number density and turbulence. Since Sc is small and PMWE occurrence is low, this will be a very difficult task. It is presumably easier to detect these particles directly by in-situ techniques as is planned in several projects in the near future.

Acknowledgements. We thank M. Zecha for providing important information on the mean characteristics of PMWE. We are grateful to the staff of Andøya Rocket Range and DLR-MORABA for their professional launch services. U.-P. Hoppe and A. Brattli thank S. Olsen and T. Tønnesen, University of Troms $\varnothing$, for their efficient assistance with the PIP hardware. The radar experiments received funding from the EU 6th framework programme project ALOMAR eARI. This project was supported by the Bundesministerium für Bildung, Wissenschaft, Forschung und Technologie, Bonn, under grant 50 OE 9901.

Edited by: W. Ward

\section{References}

Achatz, U. and Schmitz, G.: Shear and static instability of inertiagravity-wave packets: Short-term modal and non modal growth, J. Atmos. Sci., in press, 2006.

Becker, E., Müllemann, A., Lübken, F.-J., Körnich, H., Hoffmann, P., and Rapp, M.: High Rossby-wave activity in Austral winter 2002: Modulation of the general circulation of the MLT during the MaCWAVE/MIDAS northern summer program, Geophys. Res. Lett., 31, doi:10.1029/2004GL019615, 2004.

Becker, E.: Direct heating rates associated with gravity wave saturation, J. Atmos. Solar Terr. Phys., 66, doi:10.1016/j.jastp.2004.01.019, 2004.

Blix, T. A., Thrane, E. V., and Andreassen, Ø.: In-situ measurements of fine-scale structure and turbulence in the mesosphere and lower thermosphere by means of electrostatic positive ion probes, J. Geophys. Res., 95, 5533-5548, 1990a.

Blix, T. A., Thrane, E. V., Fritts, D. C., von Zahn, U., Lübken, F.J., Hillert, W., Blood, S. P., Mitchell, J. D., Kokin, G. A., and Pakhomov, S. V.: Small scale structure observed in-situ during MAC/EPSILON, J. Atmos. Terr. Phys., 52, 835-854, $1990 \mathrm{~b}$.
Czechowsky, P., Rüster, R., and Schmidt, G.: Variations of mesospheric structures in different seasons, Geophys. Res. Lett., 6, 459-462, 1979.

Driscoll, R. J. and Kennedy, L. A.: A model for the spectrum of passive scalars in an isotropic turbulence field, Phys. Fluids, 28, 72-80, 1985.

Ecklund, W. L. and Balsley, B. B.: Long-term observations of the Arctic mesosphere with the MST radar at Poker Flat, Alaska, J. Geophys. Res., 86, 7775-7780, 1981.

Friedrich, M., Harrich, M., Steiner, R. J., Torkar, K. M., and Lübken, F.-J.: The quiet auroral ionosphere and its neutral background, Adv. Space Res., 33, 943-948, 2004.

Fritts, D. C. and Alexander, J.: Gravity wave dynamics and effects in the middle atmosphere, Rev. Geophys., 41(1), doi:10.1029/2001RG000106, 2003.

Fritts, D. C., Bizon, C., Werne, J., and Meyer, C.: Layering accompanying turbulence generation due to shear instability and gravity wave breaking, J. Geophys. Res., 108(D8), 8452, doi:10.1029/2002JD002406, 2003.

Giebeler, J.: In-situ Messungen zur Untersuchung der Rolle von Turbulenz bei der Erzeugung von Radarechos in der polaren Mesosphäre im Sommer, PhD thesis, Bonn University, BONNIR-95-28, 1995.

Goldberg, R. A., Fritts, D. C., Williams, B. P., Lübken, F.-J., Rapp, M., Singer, W., Latteck, R., Hoffmann, P., Müllemann, A., Baumgarten, G., Schmidlin, F. J., She, C.-Y., and Krueger, D. A.: The MacWAVE/MIDAS rocket and ground-based measurement of polar summer dynamics: overview and mean state structure, Geophys. Res. Lett., 31, doi:10.1029/2004GL019411, 2004.

Hill, R. J.: Non-neutral and quasi-neutral diffusion of weakly ionized multi-constituent plasma, J. Geophys. Res., 83, 989-998, 1978.

Hocking, W. K.: On the extraction of atmospheric turbulence parameters from radar backscatter Doppler spectra - I. Theory, J. Atmos. Terr. Phys., 45, 89-102, 1983.

Kirkwood, S., Barabash, V., Belova, E., Nilsson, H., Rao, T. N., Stebel, K., Osepian, A., and Chilson, P. B.: Polar Mesosphere Winter Echoes during Solar Proton Events, Adv. Polar Upper Atmos. Res., 16, 111-125, 2002.

Kirkwood, S., Belova, E., Dalin, P., Fricke, K.-H., Blum, U., Schmidlin, F., and Goldberg, R. A.: Polar Mesosphere winter echoes during MaCWAVE, in: Proceedings of the 16th ESA Symposium on European Rocket and Balloon Programmes and Related Research, St. Gallen, Switzerland, edited by: Warmbein, B., vol. ESA SP-530, pp. 357-362, 2003.

Latteck, R., Singer, W., and Bardey, H.: The ALWIN MST radar Technical design and performances, in: Proceedings of the 14th ESA Symposium on European Rocket and Balloon Programmes and Related Research, Potsdam, Germany, edited by: KaldeichSchürmann, B., vol. ESA SP-437, pp. 179-184, 1999.

Lübken, F.-J.: On the extraction of turbulent parameters from atmospheric density fluctuations, J. Geophys. Res., 97, 20385$20395,1992$.

Lübken, F.-J.: Seasonal variation of turbulent energy dissipation rates at high latitudes as determined by in-situ measurements of neutral density fluctuations, J. Geophys. Res., 102, $13441-$ $13456,1997$. 
Lübken, F.-J.: Thermal structure of the Arctic summer mesosphere, J. Geophys. Res., 104, 9135-9149, 1999.

Lübken, F.-J. and von Zahn, U.: Thermal structure of the mesopause region at polar latitudes, J. Geophys. Res., 96, 20 841-20857, 1991.

Lübken, F.-J., von Zahn, U., Thrane, E. V., Blix, T., Kokin, G. A., and Pachomov, S. V.: In-situ measurements of turbulent energy dissipation rates and eddy diffusion coefficients during MAP/WINE, J. Atmos. Terr. Phys., 49, 763-775, 1987.

Lübken, F.-J., Hillert, W., Lehmacher, G., and von Zahn, U.: Experiments revealing small impact of turbulence on the energy budget of the mesosphere and lower thermosphere, J. Geophys. Res., 98, 20369-20384, 1993.

Lübken, F.-J., Giebeler, J., Blix, T., Thrane, E., Singer, W., and Bremer, J.: In-situ measurement of the Schmidt number within a PMSE layer, Geophys. Res. Lett., 21, 1651-1654, 1994.

Mechtly, E. A., Bowhill, S. A., Smith, L. G., and Knoebel, H. W.: Lower ionosphere electron concentrations and collision frequency from rocket measurements of Faraday rotation, differential absorption, and probe current, J. Geophys. Res., 72, 52395245, 1967.

Rapp, M. and Lübken, F.-J.: Polar mesosphere summer echoes (PMSE): Review of observations and current understanding, Atmos. Chem. Phys., 4, 2601-2633, 2004,

\section{SRef-ID: 1680-7324/acp/2004-4-2601.}

Rapp, M., Strelnikov, B., Müllemann, A., Lübken, F.-J., and Fritts, D. C.: Turbulence measurements and implications for gravity wave dissipation during the MacWave/MIDAS rocket program, Geophys. Res. Lett., 31, doi:10.1029/2003GL019325, 2004.

Schmidlin, F. J.: The inflatable sphere: A technique for the accurate measurement of middle atmosphere temperatures, J. Geophys. Res., 96, 22 673-22 682, 1991.
Stebel, K., Blum, U., Fricke, K.-H., Kirkwood, S., Mitchell, N. J., and Osepian, A.: Joint radar/lidar observations of possible aerosol layers in the winter mesosphere, J. Atmos. Solar Terr. Phys., 66, 957-970, 2004.

Strelnikov, B., Rapp, M., and Lübken, F.-J.: A new technique for the analysis of neutral air density fluctuations measured in situ in the middle atmosphere, Geophys. Res. Lett., 30, doi:10.1029/2003GL018271, 2003.

Tatarskii, V. I.: Wave propagation in a turbulent medium, McGrawHill Book Comp., New York, 1961.

Thrane, E., Blix, T., Hoppe, U.-P., Lübken, F.-J., Hillert, W., Lehmacher, G., and Fritts, D.: A study of small-scale waves and turbulence in the mesosphere using simultaneous in-situ observations of neutral and plasma fluctuations, J. Atmos. Terr. Phys., 56, 1797-1808, 1994.

Thrane, E. V. and Grandal, B.: Observations of fine scale structure in the mesosphere and lower thermosphere, J. Atmos. Terr. Phys., 43, 179-189, 1981.

Thrane, E. V., Andreassen, Ø., Blix, T., Grandal, B., Brekke, A., Philbrick, C. R., Schmidlin, F. J., Widdel, H.-U., von Zahn, U., and Lübken, F.-J.: Neutral air turbulence in the upper atmosphere observed during the Energy Budget Campaign, J. Atmos. Terr. Phys., 47, 243-264, 1985.

Torrence, C. and Compo, G. P.: A practical guide to wavelet analysis, Bull. Amer. Meteor. Soc., 79, 61-79, 1998.

Widdel, H. U.: Foil chaff clouds as a tool for in-situ measurements of atmospheric motions in the middle atmosphere: Their flight behaviour and implications for radar tracking, J. Atmos. Terr. Phys., 52, 89-101, 1990. 